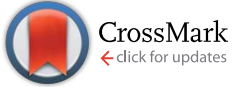

Cite this: J. Mater. Chem. A, 2015, 3, 10504

\title{
3D graphene/nylon rope as a skeleton for noble metal nanocatalysts for highly efficient heterogeneous continuous-flow reactions $\uparrow$
}

\begin{abstract}
Sai Zhang, ${ }^{a}$ Xuetao Shen, ${ }^{a}$ Zhiping Zheng, ${ }^{a}$ Yuanyuan Ma ${ }^{\star a}$ and Yongquan $\mathrm{Qu}^{\star a b}$
Continuous-flow catalytic systems represent a highly efficient approach towards scalable synthesis with features of time and energy saving, easy operation, and improved safety. Herein, we rationally design a novel 3D noble metal/graphene/nylon rope to act as a highly efficient catalyst for continuous-flow organic reactions. We show that different noble metal (Pd, Pt, Au and $\mathrm{Ag}$ ) nanocatalysts and graphene can be readily assembled with the chemically inert nylon rope by a one-step hydrothermal method. Graphene, acting as the interconnector for noble metal nanoparticles and the nylon rope, increases the flexibility and mechanical strength of rope-like catalysts and improves the catalytic activity and stability of the noble metal species. The large voids within the noble metal/graphene/nylon rope catalysts, under optimized reaction conditions, ensure the sufficient chemical transfer for the continuous-flow system. The high catalytic activity and stability of rope catalysts are demonstrated by the Suzuki-Miyaura crosscoupling reaction (SMC) and 4-nitrophenol reduction reaction. Pd/graphene/nylon rope catalysts show a high turnover number of $965 \mathrm{~mol} \mathrm{~h}^{-1}$ mol $_{\mathrm{Pd}}{ }^{-1}$, a large productivity of $1385 \mathrm{mg} \mathrm{h}^{-1} \mathrm{mg}_{\mathrm{Pd}}{ }^{-1}$ at a flow rate of $70 \mathrm{~mL} \mathrm{~h}^{-1}$, and a remarkable stability for continuous-flow SMC reactions. Such a novel minifluidic system integrated with 3D noble metal/graphene/nylon rope catalysts can be extended to many important chemical reactions.
\end{abstract}

Received 18th January 2015

Accepted 7th April 2015

DOI: $10.1039 / \mathrm{c} 5 \mathrm{ta} 00409 \mathrm{~h}$

www.rsc.org/MaterialsA the presence of additives. ${ }^{12-15}$ However, such homogeneous continuous-flow systems raise difficulties in product purification and catalyst recovery. To develop a continuous-flow system that combines immobilized catalysts on solid supports has the potential to address the inconveniences of homogeneous systems. ${ }^{9}$ Catalysts anchored on the surfaces of silica, ${ }^{16}$ aluminium oxide, ${ }^{17,18}$ and polymer beads ${ }^{19,20}$ packed into the continuous-flow column have been reported to benefit the separation of catalysts from products and reuse of the catalysts. However, the elemental analysis indicates a gradual bleaching of catalytically active species into the reaction solution, which may result in a continuously decreased catalytic efficiency of the system..$^{21-23}$ Besides, the swelling of the polymer supports in organic solvents and chemical instability of metal oxides under harsh conditions further increase the complexity of the heterogeneous catalysts in continuous-flow systems. The selected solvents and additives are also limited by the polymers and metal oxides, which may react or dissolve in the reaction media. Therefore, it is still greatly significant and challenging to seek for a support with high structural stability under harsh reaction conditions, and thus increase the activity of the catalysts and reduce bleaching of the catalytic active components.

The mono or multilayer of chemically exfoliated graphene with many advantages, such as large surface area and porosity, excellent mechanical strength, outstanding chemical stability, and high electronic conductivity, holds great technical potential 
as an ideal support for heterogeneous catalysis. ${ }^{\mathbf{2 4 - 2 8}}$ Noble metal graphene composites have been widely explored for chemical reactions, with improved catalytic activity and enhanced durability. ${ }^{29-32}$ Recently, the synthesis and applications of three dimensional (3D) graphene and its composites with metal/ metal oxides have attracted considerable attention in the areas of catalysis, energy storage, and environmental remediation. ${ }^{33-35}$ For example, the $3 \mathrm{D} \mathrm{Pd} /$ graphene presents high activity for the Heck $\mathrm{C}-\mathrm{C}$ coupling reaction. ${ }^{36}$ To the best of our knowledge, the investigations on continuous-flow systems integrated with 3D graphene have not been reported, despite the numerous advantages of graphene for catalytic reactions. This could be attributed to the randomly distributed macroscale pores of 3D graphene, which may result in uncontrollable fluid dynamics, limited liquid flow rates, and clogged flow channels. Moreover, the less easily tailored geometric configuration, size, and structural collapse of wet 3D graphene and its composites with slight bending or stretching make them incompatible with the shaped-reactors.

Herein, we report a uniform model for the assembly of a novel 3D macroscale noble metal/graphene/nylon rope as a catalytic fixed-bed incorporated for continuous-flow minifluidic systems. We selected the nylon rope $\left(8.33 \mathrm{mg} \mathrm{cm}{ }^{-1}\right.$, specific surface area $=0.015 \mathrm{~m}^{2} \mathrm{~g}^{-1}, \phi=1.5 \mathrm{~mm}$ ) as the skeleton for the assembled noble metal/graphene due to its excellent chemical inertness, high structural stability and flexibility under harsh conditions, and tens of micron-scaled voids within the rope for efficient liquid flow. Graphene, which acts as the interconnector for the noble metal nanoparticles and nylon rope, increases the flexibility and mechanical strength of the noble metal/graphene/nylon rope and improves the catalytic activity of the noble metal species. The noble metal nanoparticles anchor onto the graphene sheet and could be stabilized in the porous graphene structure. The high catalytic efficiency and remarkable stability of Pd/graphene/ nylon ropes (PdGN) are demonstrated by a proof-of-concept reaction of the Suzuki-Miyaura cross-coupling (SMC) between iodobenzene and phenylboronic acid. With the continuousflow system, a high productivity (1385 $\mathrm{mg} \mathrm{h}^{-1} \mathrm{mg}_{\mathrm{Pd}}{ }^{-1}$ ) and a large turnover number (TON, $965 \mathrm{~mol} \mathrm{~h}^{-1} \mathrm{~mol}_{\mathrm{Pd}}{ }^{-1}$ ) are achieved at a high flow rate of $70 \mathrm{~mL} \mathrm{~h}^{-1}$ with a short residence time of $1.7 \mathrm{~min}$, which are 5.0 and 4.3 times higher than those for batch synthesis with the same amount of reactants for $1 \mathrm{~h}$ flowing through the continuous-flow system. The successfully assembled Pt/graphene/nylon rope (PtGN), Au/graphene/nylon rope $(\mathrm{AuGN})$, and $\mathrm{Ag} / \mathrm{graphene} /$ nylon rope $(\mathrm{AgGN})$ prove that this is a uniform model for the fabrication of noble metal/ graphene/nylon rope catalysts (NMGN). Their catalytic activity and remarkable stability are also demonstrated by another model reaction for the chemical reduction of 4-nitrophenol.

\section{Results and discussion}

The synthetic approach of PdGN catalysts is facile and straightforward with a one-step hydrothermal method at $120{ }^{\circ} \mathrm{C}$ in a mixed solution containing a clean nylon rope, graphene oxides, $\mathrm{Na}_{2} \mathrm{PdCl}_{4}$ and glucose. As shown in the optical images (Fig. 1a a
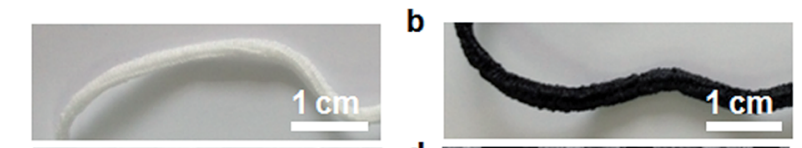

C

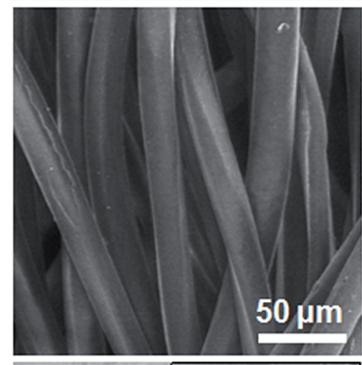

e

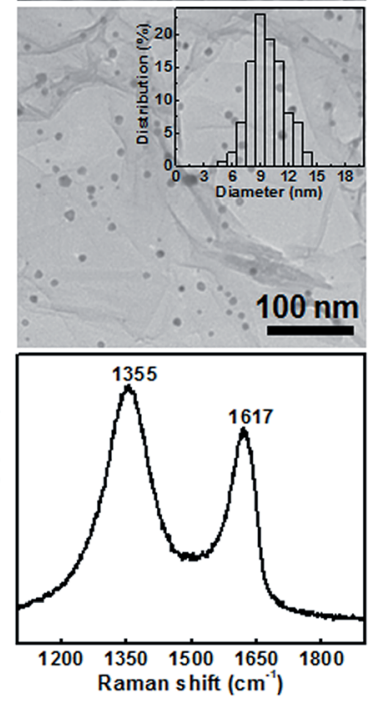

g

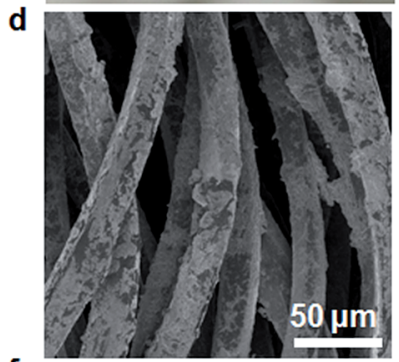

f

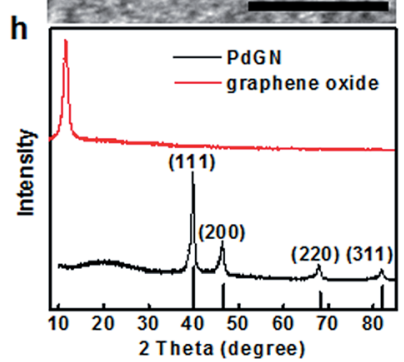

Fig. 1 Structural characterization of the PdGN catalysts. (a) Optical image of the clean nylon rope. (b) Optical image of as-synthesized PdGN catalysts. (c) SEM image of the clean nylon rope. (d) SEM image of PdGN catalysts. (e) TEM and (f) HRTEM images of Pd nanoparticles anchored on graphene obtained from 30 min ultrasonication of PdGN catalysts in ethanol. The inset is the size distribution of $\mathrm{Pd}$ nanoparticles loaded on PdGN catalysts. (g) Raman spectrum of PdGN catalysts. (h) XRD patterns of PdGN catalysts and graphene oxides.

and b) for the nylon rope before the hydrothermal treatment and PdGN catalysts, the color evolution from white to black indicates the successful assembly of Pd nanoparticles, graphene, and nylon rope. In contrast, the hydrothermal treatments on the nylon rope in the absence of the Pd precursor and graphene oxide did not induce color change of the rope (Fig. S1c, $\operatorname{ESI} \dagger$ ). Their microstructures are further characterized by scanning electron microscopy (SEM) and transmission electron microscopy (TEM). Compared to the smooth surface of the nylon rope (Fig. 1c), the corrugated surface of the fibers of PdGN (Fig. 1d) indicate the conjugation of graphene with the nylon rope. The TEM image given in Fig. 1e exhibits the co-existence of Pd nanocatalysts with a size distribution of $9.74 \pm 1.8 \mathrm{~nm}$. Glucose is necessary in the formation of PdGN catalysts. It reduces not only the graphene oxide but also the $\mathrm{Na}_{2} \mathrm{PdCl}_{4}$ salt to form $\mathrm{Pd}$ nanoparticles within the PdGN catalysts. The Raman spectrum of the PdGN catalysts (Fig. 1g) displays typical Raman peaks of reduced graphene oxides, namely the D-band at $1355 \mathrm{~cm}^{-1}$ and G-band at $1617 \mathrm{~cm}^{-1}$, which confirms the presence of graphene 
on the nylon rope. A high resolution TEM (HRTEM) study of Pd nanoparticles showed that nanoparticles have a clear crystalline structure (Fig. 1f). The crystal domains of nanoparticles have an inter-fringe distance of $0.228 \mathrm{~nm}$, which is close to the lattice spacing of the (111) planes of the face-centered cubic Pd crystal $(0.223 \mathrm{~nm})$. The XRD patterns of the graphene oxide and PdGN catalysts are shown in Fig. $1 \mathrm{~h}$. The broad peak centred at $26^{\circ}$ of PdGN catalysts further indicates the existence of graphite carbon and confirms the chemical reduction of graphene oxides during the hydrothermal process. The XRD patterns additionally indicate the formation of Pd nanoparticles. The peak centred at $39.91^{\circ}, 43.6^{\circ}, 67.9^{\circ}$ and $81.8^{\circ}$ correspond to the (111), (200), (220), and (311) Bragg reflections, respectively. The presence of rGOs also can be reflected in the specific surface area of the catalysts. The measured surface area of $0.057 \mathrm{~m}^{2} \mathrm{~g}^{-1}$ for ropelike catalysts was 3.8 times higher than that of the nylon rope, suggesting the successful conjugation between the nylon rope and graphene. The loading of the reduced graphene oxide in the 3D PdGN catalysts was $6.2 \mathrm{mg} \mathrm{g}^{-1}$, which was calculated by the equation shown in the ESI. $\dagger$

The presence of graphene is also important for the formation of 3D PdGN catalysts. Firstly, it acts as the connector between the noble metal nanoparticles and nylon rope, which increases Pd loading compared with the nylon rope. A parallel synthesis to PdGN catalysts was carried out in the absence of graphene oxide, which gave a brown color to the rope (Fig. S1d, ESI†). Inductively coupled plasma optical emission spectroscopy (ICP-OES) analysis indicates only a small Pd loading of $631 \mu \mathrm{g} \mathrm{g}^{-1}$, which is 3.1 times lower than that of PdGN catalysts $\left(1956 \mu \mathrm{g} \mathrm{g}^{-1}\right)$. Secondly, graphene not only functions as a strong interconnector between the Pd nanoparticles and nylon rope but also enhances the stability of the catalysts. No small broken fragments could be observed upon stretching of the PdGN catalysts (Fig. S2 and Video S1, ESI $\dagger$ ). The Pd nanoparticles anchored and stabilized onto the graphene could depress the bleaching of the catalytically active Pd species. ${ }^{37}$ The presence of graphene can increase the catalytic activity of the noble metal catalyst due to the synergetic effect between noble metal and graphene, which has been well reported in heterogeneous catalyst systems. ${ }^{36,38}$

The loading of catalytic active Pd nanoparticles can be accurately controlled by varying the length of the nylon rope and the initial concentration of the Pd precursor. As shown in Fig. S3, $\dagger$ with $35 \mathrm{~mL}$ of the $\mathrm{Pd}^{2+}$ precursor at a concentration of $280 \mu \mathrm{g} \mathrm{mL}{ }^{-1}$, the increase of the length of the nylon rope from $30 \mathrm{~cm}$ to $70 \mathrm{~cm}$ led to a decreased Pd loading from $1989 \mu \mathrm{g} \mathrm{g}^{-1}$ to $1660 \mu \mathrm{g} \mathrm{g}^{-1}$. Keeping the length of the nylon rope of $50 \mathrm{~cm}$ in $35 \mathrm{~mL}$ of the Pd precursor solution, the amount of the loaded Pd linearly increased from $1339 \mu \mathrm{g} \mathrm{g}^{-1}$ to $3032 \mu \mathrm{g} \mathrm{g}^{-1}$ with the increase of the initial concentration of $\mathrm{Pd}^{2+}$ from $90 \mu \mathrm{g} \mathrm{mL} \mathrm{m}^{-1}$ to $470 \mu \mathrm{g} \mathrm{mL} \mathrm{m}^{-1}$. In this work, the rope-like catalysts synthesized with $50 \mathrm{~cm}$ of nylon ropes in $35 \mathrm{~mL}$ of the Pd precursor solution at a concentration of $280 \mu \mathrm{g} \mathrm{mL} \mathrm{m}^{-1}$ were used for the SMC reactions.

In continuous-flow synthetic chemistry, high synthetic efficiency is the most important advantage compared with batch processes. Flow velocity and mass/heat transfer are the main influencing factors for synthetic efficiency. However, they are mutually contradictory for continuous-flow systems. For a specific continuous-flow system, high flow velocity always weakens the mass/heat transfer. Herein, microstructures of PdGN catalysts offer multiple advantages to minimize or solve this contradiction. First of all, the large voids in PdGN catalysts guarantee the high flow rate of the liquid phase. The voids in PdGN catalysts becoming even larger than those of the clean nylon rope is of importance as shown in Fig. 1c and d. Hence, more favorable liquid flow within PdGN catalysts is expected. As tested in our system, a flow rate of $300 \mathrm{~mL} \mathrm{~h}^{-1}$ did not cause blockage of the reactor. Secondly, the rope-like catalysts can introduce turbulence of the flowing liquids, increasing the possibility of interaction between reactants and Pd nanocatalysts, and assuring more uniformly distributed reactants in the flowing liquid and efficient chemical transfer. Thirdly, high flexibility and mechanical strength of both nylon rope and graphene make PdGN catalysts compatible to any shaped reactors. Moreover, the high chemical and structural stability of both graphene and nylon rope make PdGN catalysts compatible with various solvents and harsh reaction conditions.

The SMC reaction of iodobenzene and phenylboronic acid, as the proof-of-concept demonstration, is used to evaluate the catalytic activity of the PdGN in a continuous-flow system shown in Fig. 2. The DMF solution containing iodobenzene, phenylboronic acid, and an aqueous $\mathrm{K}_{2} \mathrm{CO}_{3}$ solution were mixed completely in a beaker. The mixture was pumped into a homemade U-shaped reactor loaded with PdGN catalysts (Fig. S4, ESI $\dagger$ ). The conversion of the continuous-flow SMC reactions under various conditions is monitored by gas chromatography-mass spectrometry (GC-MS). The inner diameter of the homemade U-shaped reactor is changed regularly. The large inner diameter $(4 \mathrm{~mm})$ ensures the successful passing of high flow velocity liquids. The small inner diameter $(2 \mathrm{~mm})$, similar to the diameter of the PdGN rope, improves the turbulence of the flowing liquids and the interaction between liquids and Pd nanoparticles and immobilizes the PdGN catalysts in the reactor.

With the initial concentrations of iodobenzene $(0.125 \mathrm{M})$ and phenylboronic acid $(0.15 \mathrm{M})$ in DMF, the conversion of

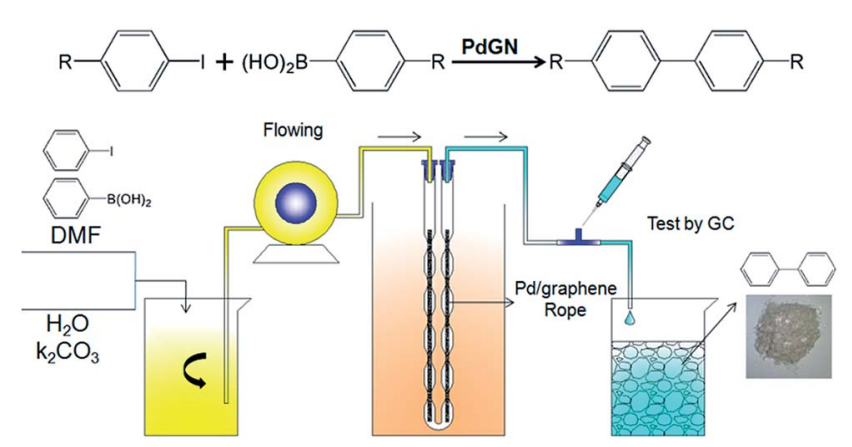

Fig. 2 Schematic representation of the continuous-flow system of Suzuki-Miyaura cross-coupling reactions catalyzed by the Pd/graphene/nylon rope. The reaction is performed in a mixture solvent of DMF and water with a volume ratio of $1: 1$ at $90{ }^{\circ} \mathrm{C}$ at various flow rates. 
iodobenzene and yield of the biphenyl (confirmed by ${ }^{1} \mathrm{H}$ NMR spectroscopy, Fig. S5, ESI $\dagger$ ) under different conditions is summarized in Tables 1, 2 and Fig. 3. At a flow velocity of $20 \mathrm{~mL} \mathrm{~h}^{-1}$ (Entry 1), the achieved conversion of iodobenzene reached $100 \%$ with a biphenyl yield of $97.1 \%$ for the PdGN catalysts. The control experiments of the nylon rope alone (Entry 2) and the graphene/nylon rope (Entry 3) exhibit no catalytic activity towards the SMC reaction, indicating that the naturally active sites of the integrated Pd corresponded to carbon-carbon coupling reactions. Another control experiment of the $\mathrm{Pd} /$ nylon rope gives a $19.1 \%$ conversion and $19.0 \%$ yield (Entry 4 ). The conversion using PdGN catalysts is 5 times higher than the one using the $\mathrm{Pd} /$ nylon rope with only 3.1 times Pd loading. The results indicate that the presence of graphene can indeed enhance the catalytic activity of Pd catalysts. This can be attributed to the synergetic catalytic effect between the catalytically active component of Pd nanoparticles and functional graphene, in which the rich $-\mathrm{OH}$ functional group of graphene donates electrons to $\mathrm{Pd}$ and accelerates the first step of the oxidative addition reaction for SMC reactions. ${ }^{28}$

To examine the contribution of the nylon rope for the catalytic reaction, the $\mathrm{Pd} /$ graphene $(\mathrm{PdG})$ catalysts were also prepared in the absence of the nylon rope. As-synthesized PdG had a $3 \mathrm{D}$ configuration, similar to the previous report. ${ }^{36}$ For the

Table 1 SMC catalytic activity of catalysts at a flow rate of $20 \mathrm{~mL} \mathrm{~h}^{-1}$

\begin{tabular}{llccc}
\hline Entry & Catalyst & $\begin{array}{l}\text { Loaded Pd } \\
(\mu \mathrm{g})\end{array}$ & $\begin{array}{l}\text { Conversion } \\
(\%)\end{array}$ & $\begin{array}{l}\text { Yield } \\
(\%)\end{array}$ \\
\hline 1 & $\begin{array}{l}\text { Pd/graphene/nylon } \\
\text { rope }\end{array}$ & 489 & 100.0 & 97.0 \\
& Nylon rope & 0 & 0 & 0 \\
3 & Graphene/nylon rope & 0 & 0 & 0 \\
4 & Pd/nylon rope & 157.8 & 19.7 & 19.0
\end{tabular}

SMC reaction, the 3D PdG was broken into pieces through sonications. The PdG with equivalent weight to the effective mass of Pd and graphene in PdGN was used. The SMC reactions between iodobenzene and phenylboronic acid catalyzed by PdGN and PdG were evaluated in a glass bottle for $1 \mathrm{~h}$. As shown in Table S1 (ESI $\dagger$ ), PdG catalysts showed a higher yield (88.9\%) of biphenyl compared with PdGN catalysts (79.6\%), indicating that the nylon rope may not contribute to the SMC reactions but function as the 3D skeleton. The relatively low yield of the product may be attributed to the poor dispersion of the ropelike catalysts compared to the well dispersed PdG catalysts in solution. However, the flow channels were blocked when 3D or broken pieces of PdG catalysts were used for the continuousflow reaction. Hence, the nylon rope provides a 3D skeleton for efficient liquid flow.

Increasing the flow velocities of the reaction solution decreases the conversion of the reactants and the yield of the biphenyl (Entry 5-12), as shown in Table 2 and Fig. 3a. For example, the yields of the product were reduced to $89.1 \%, 54.9 \%$ and $36.2 \%$ for flow rates of 30,60 and $90 \mathrm{~mL} \mathrm{~h}^{-1}$, respectively. Such phenomenon can be attributed to the shortened duration of the contact time between catalysts and reactants and the lower temperature of the reaction solution, as reflected by the decreased residence times with the increased flow velocities. At the lowest flow velocity of $20 \mathrm{~mL} \mathrm{~h}^{-1}$, a residence time of $6 \mathrm{~min}$ allows sufficient contact between reactants and Pd nanoparticles and efficient heat transfer between the flowing liquid and the surroundings. In contrast, the residence time for a high flow rate of $90 \mathrm{~mL} \mathrm{~h}^{-1}$ is only $1.33 \mathrm{~min}$, which may not provide efficient heat transfer to activate the SMC reaction at the expected temperature and also reduce the probability of the collision of reactants with catalytically active sites.

In order to confirm the benefits of PdGN catalysts for a continuous-flow synthesis, the SMC reactions performed through batch reactions (Entry 13-20) were also evaluated. For

Table 2 Catalytic activity of PdGN in continuous-flow and batch systems ${ }^{a, b}$

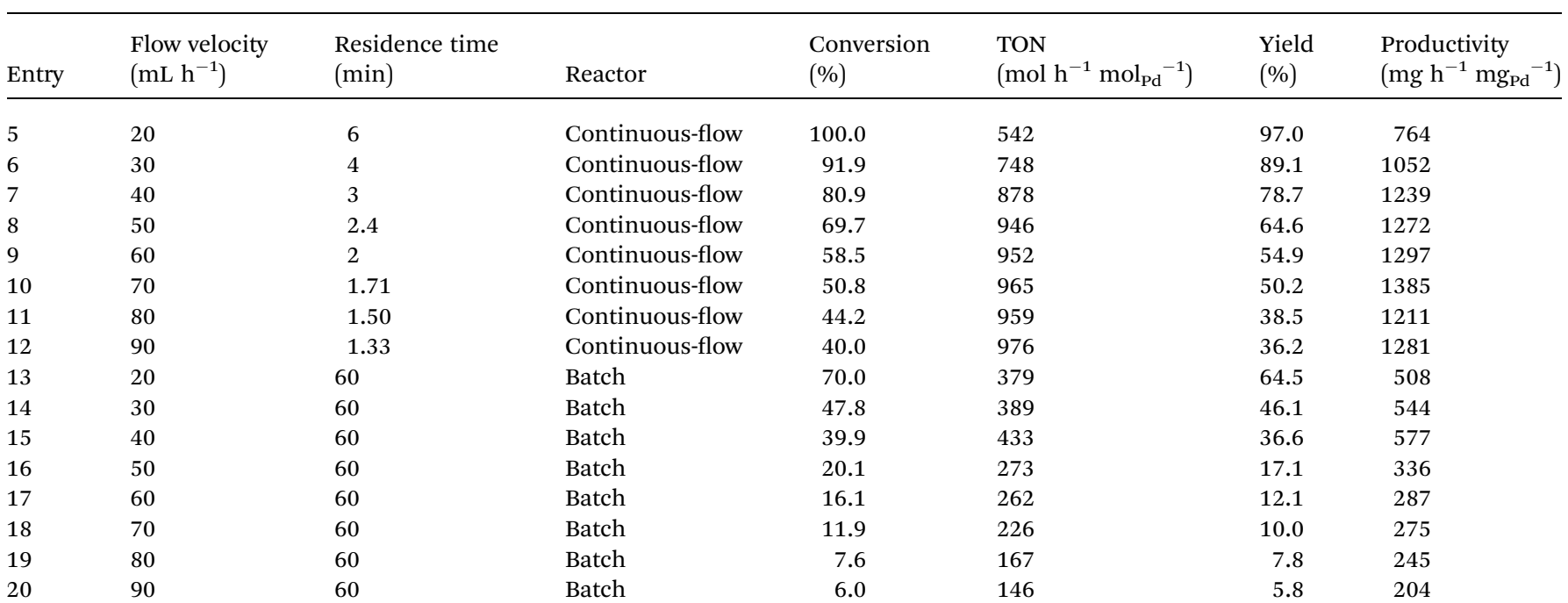

${ }^{a} \mathrm{Pd}$ loading is $489 \mu \mathrm{g}$ for all SMC reactions. ${ }^{b}$ Equal volume of reactants for continuous-flow synthesis with various flow velocities is used for the corresponding batch experiments. 
a
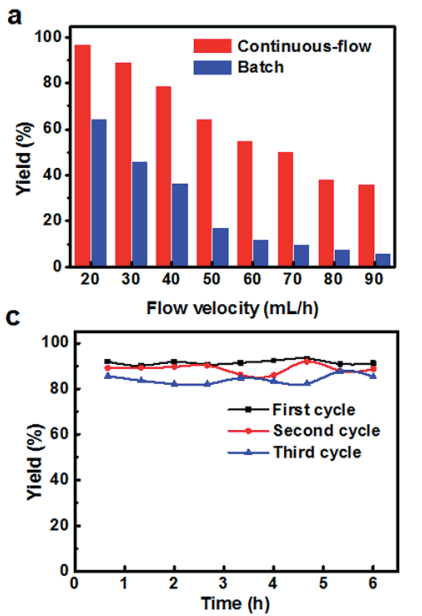

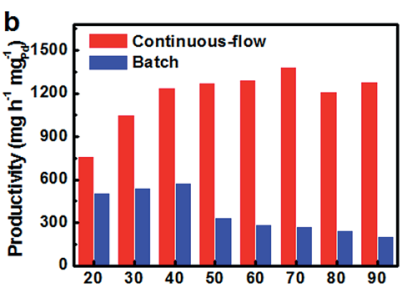

Flow velocity $(\mathrm{mL} / \mathrm{h})$

d

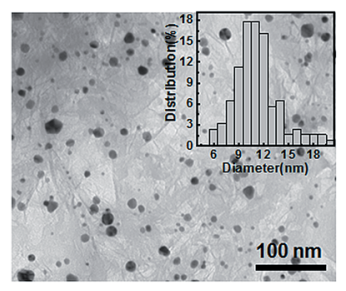

Fig. 3 Catalytic activity of PdGN in the continuous-flow reactor and batch experiments. (a) Plots of biphenyl yields at various flow rates for continuous-flow and batch experiments. (b) Plots of productivities of biphenyl at various flow rates for continuous-flow and batch experiments. (c) Catalytic stability and cyclability: plots of yields of biphenyl catalyzed by PdGN with a usage time of $6 \mathrm{~h}$ for three cycles. (d) TEM image of $\mathrm{Pd}$ nanocatalysts after finishing three cycles of the continuous-flow SMC reaction with a duration of $6 \mathrm{~h}$ for each cycle. The inset is the size distribution of $\mathrm{Pd}$ nanoparticles.

the batch reaction, the SMC reactions with equal amount of reactants that flew through the continuous-flow reactor within $1 \mathrm{~h}$ were catalyzed by the same PdGN catalysts for $1 \mathrm{~h}$. As presented in Fig. 3a, the catalytic activity of PdGN catalysts in a continuous-flow system, in terms of the yield of biphenyl, is much higher than that in the batch synthesis, although the residence times for batch reactions are much longer than those in continuous-flow systems. At the low flow rate of $20 \mathrm{~mL} \mathrm{~h}^{-1}$, the $97.1 \%$ yield of biphenyl in the continuous-flow reactor is significantly higher than $64.5 \%$ in a batch reaction, although the residence times become longer for the batch synthesis $(1 \mathrm{~h})$. The difference in the catalytic activity of PdGN in the two reaction systems is more apparent when the flow rate is increased. The conversion of iodobenzene for the continuous synthesis at a higher flow rate of $90 \mathrm{~mL} \mathrm{~h}^{-1}$ is $40 \%$, which is 6.67 times higher than that in batch experiments. The calculated turnover number (TON) of PdGN catalysts in the continuous-flow system is 542-976 $\mathrm{mol} \mathrm{h}^{-1} \mathrm{~mol}_{\mathrm{Pd}}{ }^{-1}$, which is 2.3-3.7 times higher than those in batch experiments (146-433 $\left.\mathrm{mol} \mathrm{h}^{-1} \mathrm{~mol}_{\mathrm{Pd}}{ }^{-1}\right)$. All results clearly demonstrate the high catalytic performance of PdGN catalysts for continuous-flow systems.

To further illustrate the efficiency of PdGN catalysts integrated with continuous-flow systems, the productivities of the continuous-flow systems and batch reactions, calculated by multiplying the yield and the amount of reactants flowing through the catalysts in unit time, are used to characterize the efficiency of the catalytic system. At the flow velocity of $20 \mathrm{~mL} \mathrm{~h}^{-1}$, the calculated productivity of PdGN in the continuous-flow reactor is $764 \mathrm{mg} \mathrm{h}^{-1} \mathrm{mg}_{\mathrm{Pd}}{ }^{-1}$. By increasing the flow rates, the productivity clearly shows two distinct regions: the initially increased productivity and the immediately followed decrease; the maximum productivity of $1385 \mathrm{mg} \mathrm{h}^{-1} \mathrm{mg}_{\mathrm{Pd}}{ }^{-1}$

(Entry 10) was obtained at a flow velocity of $70 \mathrm{~mL} \mathrm{~h} \mathrm{~h}^{-1}$. In contrast, the productivity of the corresponding batch synthesis is only $19.86 \%$ of the continuous-flow system at a flow velocity of $70 \mathrm{~mL} \mathrm{~h}^{-1}$ (Entry 18). As evidenced in Fig. 3b, the high productivities of PdGN catalysts integrated into a continuousflow system unambiguously illustrates the advantages of rationally designed 3D PdGN catalysts for continuous-flow reactions.

To assess the stability of PdGN catalysts, we performed the SMC reaction at a flow rate of $30 \mathrm{~mL} \mathrm{~h}^{-1}$ (4 min residence time) up to $6 \mathrm{~h}$ and repeated the experiments three times with the same PdGN catalysts. Fig. 3c shows the remarkably stable catalytic activity of PdGN with time of usage, as confirmed by a biphenyl yield of $91.3 \%$ after a $6 \mathrm{~h}$ reaction time, which was near to that $(91.9 \%)$ at $40 \mathrm{~min}$. The biphenyl yields at the end of the second and third $6 \mathrm{~h}$ cycling were slightly reduced to $88.7 \%$ and $85.3 \%$, respectively. The decreased catalytic activity could be explained by the metal bleaching and the morphological evolution of Pd nanocatalysts. ${ }^{39,40}$ The ICP-OES analysis of the reaction solution after the first of cycle reactions showed a low concentration of $50 \mathrm{ppb}$, which is much lower than those anchored on silica and polymer substrates previously reported. ${ }^{7,41,42}$ Fig. S6† shows the macroscale image of PdGN catalysts after the completion of three cycles of the continuous-flow SMC reaction at a flow rate of $30 \mathrm{~mL} \mathrm{~h}^{-1}$, and there are almost no differences compared with the initial PdGN catalysts (Fig. 1b). The TEM images of Pd nanoparticles anchored on graphene could clearly show their microscopic changes. Compared with the size of as-synthesized Pd nanoparticles of PdGN (Fig. 1e), the larger nanoparticles with sizes over $15 \mathrm{~nm}$ and the bigger average size of $10.9 \pm 2.7 \mathrm{~nm}$ (Fig. 3d) may respond to the slightly reduced activity of PdGN catalysts. ${ }^{39,40}$ Nevertheless, appropriately designed PdGN catalysts show a remarkable ability to reserve the catalytically active Pd species within the catalysts, compared to previous reports of Pd-loaded silica and polymers. ${ }^{43-45}$

With the present catalytic system, the scope of the continuous-flow SMC reactions with various aryl halides and phenylboronics was investigated at $20 \mathrm{~mL} \mathrm{~h}^{-1}$ (Table 3). Bromobenzene, another common aryl halide for the SMC reaction, was evaluated in this catalytic system. The conversion was $31.4 \%$ at a flow velocity of $20 \mathrm{~mL} \mathrm{~h}^{-1}$ (Entry 21), which was much lower than that of iodobenzene. On decreasing the flow velocity to $5 \mathrm{~mL} \mathrm{~h}^{-1}$, the conversion of bromobenzene was improved to $61.0 \%$ (Entry 22). This can be ascribed to the lower reactivity of bromobenzene for the SMC reaction compared to iodobenzene. The productivity also reached $120 \mathrm{mg} \mathrm{h}^{-1} \mathrm{mg}_{\mathrm{Pd}}{ }^{-1}$ at a flow rate of $5 \mathrm{~mL} \mathrm{~h}^{-1}$. Notably, the conversion of iodobenzene with electron donating functional groups $\left(\mathrm{OCH}_{3}\right.$ and $\mathrm{CH}_{3}$, Entry 25 and 26) and weak electron withdrawing functional group (CHO, Entry 23) reached 100\% with $100 \%$ selectivity. Because of the strong electron withdrawing effect of $-\mathrm{NO}_{2}$, the conversion of 4-iodonitrobenzene was $33.75 \%$ (Entry 24). Meanwhile, the alternatives of phenylboronics with both electron-donating groups $\left(\mathrm{CH}_{3}\right.$ and $t$-Bu) and electron withdrawing substituents (CHO and phenyl) exhibited high catalytic activity and selectivity for the SMC reactions (Entry 27-30). 
Table 3 Continuous-flow SMC reaction of different reactants ${ }^{a}$

Entry

${ }^{a}$ Unless otherwise noted, the reaction conditions are: $R_{1}(0.125 \mathrm{M}), R_{2}(0.15 \mathrm{M})$, base $(0.375 \mathrm{M})$, flow velocity of $20 \mathrm{~mL} \mathrm{~h}^{-1}$, and temperature of $90{ }^{\circ} \mathrm{C}$. Pd loading is also $489 \mu \mathrm{g} .{ }^{b}$ The ratio of DMF and $\mathrm{H}_{2} \mathrm{O}$ was adjusted to dissolve the reactants completely. ${ }^{c}$ The flow velocity is $5 \mathrm{~mL} \mathrm{~h}^{-1}$.

The synthetic strategy for PdGN catalysts also can be explored as a general approach towards metal nanocatalysts/ graphene/nylon rope catalysts with a $3 \mathrm{D}$ configuration. The synthesis of PtGN, AuGN, and AgGN was performed under similar conditions as for PdGN, except that $\mathrm{NaPdCl}_{4}$ was replaced by $\mathrm{H}_{2} \mathrm{PtCl}_{6}, \mathrm{HAuCl}_{4}$ and $\mathrm{AgNO}_{3}$, respectively. The black color of as-synthesized ropes (Fig. $4 \mathrm{a}-\mathrm{c}$ ) indicates the successful conjugations of graphene and nylon ropes. They displayed similar 3D morphological features to PdGN, as presented in the SEM images (Fig. 4d-f). Compared to the smooth surface of the nylon rope (Fig. 2c), the corrugated surface of the fibers further confirms the formation of $3 \mathrm{D}$
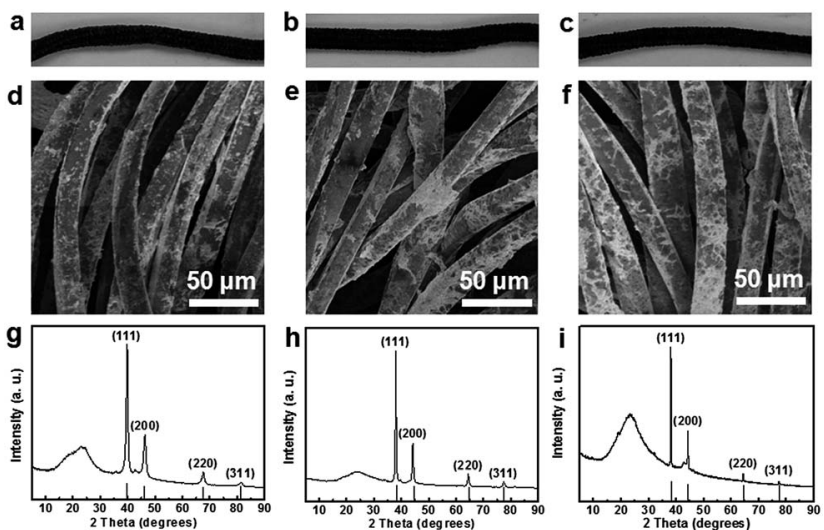

Fig. 4 Structural characterization of noble metal graphene rope catalysts. ( $a, b$ and $c)$ Optical images of as-synthesized PtGN, AuGN and AgGN catalysts. (d, e and f) SEM images of PtGN, AuGN, and AgGN catalysts. (g, h and i) XRD patterns of PtGN, AuGN and AgGN catalysts. frameworks of the rope-like catalysts. The XRD patterns (Fig. 4g-i) and TEM images (Fig. S7, ESI $\dagger$ ) indicate the formation of $\mathrm{Pt}, \mathrm{Au}$, and $\mathrm{Ag}$ nanoparticles. ICP-OES results additionally exhibited $\mathrm{Pt}, \mathrm{Au}$, and Ag loadings of $1766 \mu \mathrm{g} \mathrm{g}^{-1}$, $1236 \mu \mathrm{g} \mathrm{g}^{-1}$ and $2465 \mu \mathrm{g} \mathrm{g}^{-1}$ in the $3 \mathrm{D}$ catalysts, respectively. Similar to PdGN, the loading of the noble metal nanocatalysts in the presence of graphene was dramatically larger than that in the absence of graphene, as shown in Table S2 (ESI $\dagger$ ).

Chemical reduction of 4-nitrophenol was used to prove the presence of the noble metals in the $3 \mathrm{D}$ graphene/nylon rope and evaluate their catalytic activity for the continuousflow system. This reaction is one of the model reactions for evaluating the catalytic activity of various noble metal nanoparticles, such as $\mathrm{Ag}$, $\mathrm{Au}$, and $\mathrm{Pd}$, in different substrates. ${ }^{46-48}$ The reaction was performed using the same system as shown in Fig. 2 with initial concentrations of 4-nitrophenol $(1 \mathrm{mM})$ and $\mathrm{NaBH}_{4}(50 \mathrm{mM})$. As shown in Fig. 5a, 4-nitrophenol could not be reduced by the nylon rope and graphene/nylon rope, while all the noble metal/graphene nylon ropes show excellent catalytic activity for the reduction of 4-nitrophenol. Although the catalytic activities are different, the stability of all these noble metal/graphene/ nylon rope catalysts are remarkable. Fig. 5b shows the remarkably stable catalytic activity of noble metal/graphene/ nylon ropes with a time of $6.5 \mathrm{~h}$. The conversion for all noble metal/graphene/nylon ropes are slightly reduced by less than $5 \%$. The ICP-OES analysis of the reaction solution shows a low concentration of $5.99 \mathrm{ppb}(\mathrm{Pd}), 10.79 \mathrm{ppb}(\mathrm{Pt}), 2.30 \mathrm{ppb}$ $\mathrm{Au}$ ) and $2.35 \mathrm{ppb}(\mathrm{Ag})$, further confirming that graphene can reduce metal bleaching. Therefore, these noble metal/ 

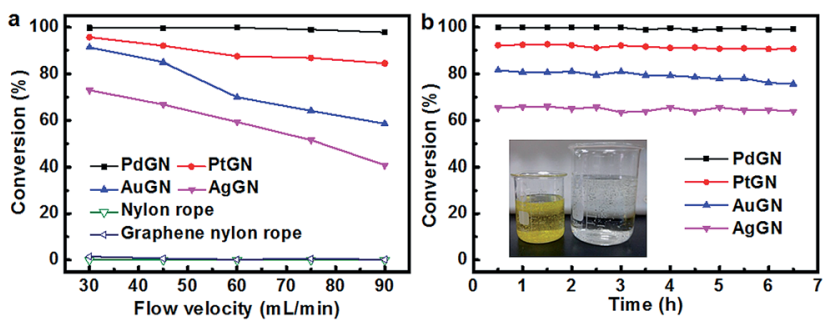

Fig. 5 Catalytic activity and stability of noble metal/graphene/nylon rope catalysts for the reduction of 4-nitrophenol in the continuousflow reactor. (a) Catalytic tests for the reduction rate of the reduction of 4-nitrophenol with different noble metal/graphene/nylon ropes at different flow velocities. (b) Catalytic stability: plots of concentration of 4-nitrophenol catalyzed by different noble metal/graphene/nylon ropes with the usage time of $6.5 \mathrm{~h}$. The inset shows the color change indicating the reduction of 4-nitrophenol to 4-aminophenol.

graphene/nylon ropes have a wide range of potential applications in the organic continuous-flow reaction.

\section{Conclusions}

In summary, 3D noble metal/graphene/nylon ropes functioning as heterogeneous catalysts for continuous-flow systems have been successfully synthesized by a one-step hydrothermal method at $120^{\circ} \mathrm{C}$. The chemically inert nylon rope provides a 3D framework for macroassembled noble metal/graphene with voids of tens of microns for sufficient chemical transfer at high flow rates of the reaction solution. Graphene has multiple functions, including acting as the interconnector between the noble metal species and the nylon rope, enhancing the structural stability and mechanical strength of the noble metal/graphene rope, and increasing the catalytic activity and stability of noble metal nanocatalysts. PdGN catalysts show a high catalytic activity, productivity, and stability for continuous-flow SMC reactions compared with traditional batch reactions. The catalytic activity and stability of other noble metal/graphene/nylon rope catalysts are also demonstrated by the reduction of 4nitrophenol. The current minifluidic continuous-flow systems integrated with 3D NMGN catalysts have the potential for practical applications and can be extended to many important chemical reactions catalyzed by noble metals.

\section{Acknowledgements}

We acknowledge the financial support from the National Natural Science Foundation of China (21201138). This work was also partially funded by the Ministry of Science and Technology of China through a 973-program under the grant 2012CB619401 and supported by the Fundamental Research Funds for the Central Universities (xjj2013102 and xjj2013043). Technical supports for TEM experiments from Frontier Institute of Science and Technology and State Key Laboratory for Mechanical Behavior of Materials, Xi'an Jiaotong University, are also acknowledged.

\section{Notes and references}

1 F. Lévesque and P. H. Seeberger, Angew. Chem., Int. Ed., 2012, 51, 1706-1709.

2 D. Webb and T. F. Jamison, Chem. Sci., 2010, 1, 675-680.

3 J. C. Pastre, D. L. Browne and S. V. Ley, Chem. Soc. Rev., 2013, 42, 8849-8868.

4 S. Marre and K. F. Jensen, Chem. Soc. Rev., 2010, 39, 11831202.

5 L. Zhang and Y. Xia, Adv. Mater., 2014, 26, 2600-2606.

6 H. Kim, A. Nagaki and J.-I. Yoshida, Nat. Commun., 2011, 2, 264.

7 J. Wegner, S. Ceylan and A. Kirschning, Chem. Commun., 2011, 47, 4583-4593.

8 R. L. Hartman, J. P. McMullen and K. F. Jensen, Angew. Chem., Int. Ed., 2011, 50, 7502-7519.

9 T. Tsubogo, T. Ishiwata and S. Kobayashi, Angew. Chem., Int. Ed., 2013, 52, 6590-6604.

10 C. Wiles and P. Watts, Chem. Commun., 2011, 47, 6512-6535. 11 R. L. Hartman and K. F. Jensen, Lab Chip, 2009, 9, 24952507. 12 L. Ducry and D. M. Roberge, Angew. Chem., 2005, 117, 81868189.

13 A. B. Theberge, G. Whyte, M. Frenzel, L. M. Fidalgo, R. C. Wootton and W. T. Huck, Chem. Commun., 2009, 6225-6227.

14 B. Worrell, J. Malik and V. Fokin, Science, 2013, 340, 457-460. 15 W. Shu, L. Pellegatti, M. A. Oberli and S. L. Buchwald, Angew. Chem., 2011, 123, 10853-10857.

16 N. Wang, T. Matsumoto, M. Ueno, H. Miyamura and S. Kobayashi, Angew. Chem., 2009, 121, 4838-4840.

17 L. Yin and J. Liebscher, Chem. Rev., 2007, 107, 133-173.

18 A. Gniewek, J. J. Ziółkowski, A. M. Trzeciak, M. Zawadzki, H. Grabowska and J. Wrzyszcz, J. Catal., 2008, 254, 121-130.

19 E. Alza, C. Rodríguez-Escrich, S. Sayalero, A. Bastero and M. A. Pericàs, Chem.-Eur. J., 2009, 15, 10167-10172.

20 T. Yasukawa, H. Miyamura and S. Kobayashi, J. Am. Chem. Soc., 2012, 134, 16963-16966.

21 T. Noël and S. L. Buchwald, Chem. Soc. Rev., 2011, 40, 50105029.

22 K. V. Ranganath, A. H. Schäfer and F. Glorius, ChemCatChem, 2011, 3, 1889-1891.

23 G. Shore, S. Morin and M. G. Organ, Angew. Chem., 2006, 118, 2827-2832.

24 V. Georgakilas, M. Otyepka, A. B. Bourlinos, V. Chandra, N. Kim, K. C. Kemp, P. Hobza, R. Zboril and K. S. Kim, Chem. Rev., 2012, 112, 6156-6214.

25 C. Li and G. Shi, Nanoscale, 2012, 4, 5549-5563.

26 T. Xue, B. Peng, M. Xue, X. Zhong, C.-Y. Chiu, S. Yang, Y. Qu, L. Ruan, S. Jiang and S. Dubin, Nat. Commun., 2014, 5, 3200. 27 T. Xue, S. Jiang, Y. Qu, Q. Su, R. Cheng, S. Dubin, C. Y. Chiu, R. Kaner, Y. Huang and X. Duan, Angew. Chem., 2012, 124, 3888-3891.

28 G. M. Scheuermann, L. Rumi, P. Steurer, W. Bannwarth and R. Mülhaupt, J. Am. Chem. Soc., 2009, 131, 8262-8270.

29 X. Huang, X. Qi, F. Boey and H. Zhang, Chem. Soc. Rev., 2012, 41, 666-686. 
30 Y. Nishina, J. Miyata, R. Kawai and K. Gotoh, RSC Adv., 2012, 2, 9380-9382.

31 Y. Li, X. Fan, J. Qi, J. Ji, S. Wang, G. Zhang and F. Zhang, Nano Res., 2010, 3, 429-437.

32 P. Zhang, Y. Gong, H. Li, Z. Chen and Y. Wang, Nat. Commun., 2013, 4, 1593.

33 S. Nardecchia, D. Carriazo, M. L. Ferrer, M. C. Gutiérrez and F. del Monte, Chem. Soc. Rev., 2013, 42, 794-830.

34 H.-P. Cong, X.-C. Ren, P. Wang and S.-H. Yu, ACS Nano, 2012, 6, 2693-2703.

35 Z.-Y. Wu, C. Li, H.-W. Liang, J.-F. Chen and S.-H. Yu, Angew. Chem., Int. Ed., 2013, 52, 2925-2929.

36 Z. Tang, S. Shen, J. Zhuang and X. Wang, Angew. Chem., Int. Ed., 2010, 49, 4603-4607.

37 Z. Jin, D. Nackashi, W. Lu, C. Kittrell and J. M. Tour, Chem. Mater., 2010, 22, 5695-5699.

38 R. Kou, Y. Shao, D. Wang, M. H. Engelhard, J. H. Kwak, J. Wang, V. V. Viswanathan, C. Wang, Y. Lin, Y. Wang, I. A. Aksay and J. Liu, Electrochem. Commun., 2009, 11, 954-957.
39 R. Narayanan and M. A. El-Sayed, J. Am. Chem. Soc., 2003, 125, 8340-8347.

40 Y. Li, E. Boone and M. A. El-Sayed, Langmuir, 2002, 18, 49214925.

41 G. Shore, S. Morin and M. G. Organ, Angew. Chem., 2006, 118, 2827-2832.

42 S. Ceylan, C. Friese, C. Lammel, K. Mazac and A. Kirschning, Angew. Chem., Int. Ed., 2008, 47, 8950-8953.

43 A. Molnar, Chem. Rev., 2011, 111, 2251-2320.

44 D. D. Das and A. Sayari, J. Catal., 2007, 246, 60-65.

45 P. Wang, Q. Lu and J. Li, Catal. Lett., 2009, 131, 444-450.

46 B. Liu, Q. Wang, S. Yu, T. Zhao, J. Han, P. Jing, W. Hu, L. Liu, J. Zhang, L. D. Sun and C. H. Yan, Nanoscale, 2013, 5, 97479757.

47 B. Baruah, G. J. Gabriel, M. J. Akbashev and M. E. Booher, Langmuir, 2013, 29, 4225-4234.

48 A. Gangula, R. Podila, M. R. Ramakrishna, L. Karanam, C. Janardhana and A. M. Rao, Langmuir, 2011, 27, 1526815274. 